\title{
Reinventing the university
}

\author{
Stephen Brown \\ De Montfort University
}

In view of the discernible trends in Higher Education towards increased numbers, increased diversity and expectations of students, declining resources, increased competition between providers and increasingly irregular patterns of student attendance, there is a need to establish new ways of delivering and supporting teaching and learning. The convergence of different media into a single networked digital domain, and the rapidly expanding accessibility of such media, both driven by market forces, is tempting many $\mathrm{HE}$ institutions to develop an online presence. True 'virtual universities', i.e., completely online, are still the exception and there are strong reasons why traditional, face-to-face, universities should resist the pressure to develop a virtual alter ego. Nevertheless, online delivery and support of teaching and learning offers many potential benefits to students of such institutions, not least of which could be freedom from the constraints of conventional attendance patterns.

Since significant new resources are unlikely to be available to most UK institutions to develop online operations, existing internal resources need to be re-engineered to bring them into line behind the chosen venture. Small scale, bottom-up experiments are unlikely to succeed in re-engineering sufficient resources to achieve lasting institution-wide change. Re-engineering the campus requires a culture change, which needs to be led from the top, through an unbroken chain of champions down through the organization, including the resource managers at middle management level. A minimum of two years needs to be allowed for evaluation of the impact of change. During that initial period central coordination of, and support for, individual projects is essential to ensure delivery against targets of time, cost and quality. Nevertheless institutional change can best be achieved by encouraging local ownership, which means allowing local autonomy and avoiding premature imposition of standards.

\section{Change}

Higher Education in the UK and elsewhere is under considerable pressure to change as a result of: 
- rapid growth in student numbers

- increased variability of student intakes

- declining resources

- concerns about quality of graduates

- increased pressures for public accountability

- concerns about the relevance to industry

- increased competition from other countries and commercial interests

- increased availability and reduced costs of networked media (Brown, 1997; Cunningham et al., 1998).

These factors are driving universities to reinvent themselves. Traditional behavioural models of education are giving way to more learner-centred, collaborative experiences (Hardy, 1997). Learner-centred approaches accommodate learner needs and acknowledge that learners may have other calls on their time, leading to more flexible delivery and support strategies which allow learners to shift the time, place and pace of learning. Network technologies such as the Internet, email and computer-based and videoconferencing can assist with this process and at the same time they open up opportunities for learners to seek out and utilize learning resources offered by other parties.

\section{Coping strategies}

Complexity in the environment can be reduced by increasing the span of control of the organization (Emery and Trist, 1969). Collaborative ventures such as the University of the Highlands and Islands in Scotland (Cornwell, 1997), or Western Governors University in the USA (Romer, 1997) are examples of a trend towards mega-universities identified by Daniel (1997). 'Virtual' universities such as Western Governors (http://www.wgu.edu), California Virtual University (http://www.california.edu) and Colorado University 'CU Online' (http://www.cuonline.edu) are another way of expanding the span of influence, without requiring a physical presence. However, much of so-called online education still depends on video-conferencing, books, residential schools, etc. (Ebeling and Bistayi, 1997; Philips and Yager, 1998).

\section{Ten good reasons not to go virtual}

1. The costs of developing a virtual online presence are not yet fully understood but are considerable. In a climate of diminishing resources, investment capital has to be diverted from existing functions.

2. Competing organizations need to be able to respond rapidly and flexibly to new market requirements and competitive threats. Yet quality learning resource materials and learning support systems take longer to develop than traditional teaching.

3. Classroom teaching can be modified much more readily than resource-based learning with its longer development timescales. 
4. The infrastructure requirements of the virtual institution are quite different from those of traditional institutions and require considerable capital investment.

5. Although there is evidence that the economics of purely online education can be made to work, for a traditional university to make the transition to predominantly mixed mode would require that institution to run both systems concurrently, with all the associated costs and inevitable tensions.

6. Staff attitudes to curriculum change on this scale are often a significant barrier (Brown, 1997).

7. Student needs: not all learners are comfortable with independent learning, particularly among the traditional 18-22-year-old cohort of established universities (Hutton, 1998).

8. Reallocation of resources could weaken the traditional side of the operation at a time when competition is increasing.

9. It can be argued that there are no blueprints for converting an existing university to online mode on an institutional scale, or at least, knowledge of how to do so has not yet been unequivocally demonstrated.

10. Traditional universities have strengths that are lost in cyberspace: physical locations that provide a respite from the everyday demands of home and work; facilities and equipment that are not readily simulated in virtual space, people with whom to socialize, enjoy physical contact, chance encounters, etc.

\section{An Electronic Campus}

Instead of developing a virtual presence, De Montfort University has decided to create an Electronic Campus, in order to:

1. Enhance flexibility of access to learning on campus:

2. Develop a position that can lead to collaborative ventures with other organizations.

During 1997/8 the goal has been to:

- Develop a substantial body of HTML compliant teàching, learning and assessiment materials, which can be accessed readily by students on campus and traded with other institutions.

- Put in place appropriate learning support systems that encourage and facilitate peer group interaction and staff-student exchanges, independent of time and specific university location.

- Achieve a rapid return on investment of resources.

- Re-engineer existing resources to achieve the above.

The Electronic Campus is employing a combination of three possible implementation strategies:

- In-house development.

- Embedding of materials developed elsewhere. 
- Collaboration with other organizations to jointly develop new materials.

Pump-priming funds have been made available centrally for faculties to bid against. A proforma guides faculty staff through a set of questions designed to encourage them to consider key issues and address the selection criteria applied to proposals.

Staff IT training courses have been restructured to provide basic technical authoring skills using Microsoft Office products and more advanced Internet training on HTML authoring, web site development, Internet communications and information search techniques. Project teams are also offered short courses on the use of specific software applications used within the Electronic Campus.

\section{Impact}

\begin{tabular}{lc}
\hline Faculty & Projects \\
\hline Applied Sciences & 6 \\
Art \& Design & 5 \\
Business \& Law & 3 \\
Computing \& Engineering & 3 \\
Learning Development & 3 \\
Health \& Community Studies & 3 \\
Humanities \& Social Sciences & 4 \\
Total & 27 \\
\hline
\end{tabular}

Table I: Distribution of foculty projects

So far there are 27 different Electronic Campus projects, ranging across all faculties and at all levels including $\mathrm{FE}$, undergraduate, postgraduate and continuing professional development. Some of the projects are complete courses, some are full modules and others are parts of modules. The first of these projects will start delivering to students during the first semester of 1998.

\section{Timescale}

From the initial decision to establish an Electronic Campus (June 1997) through to delivery of the first products (October 1998) has taken 16 months. Key milestones on the way are outlined below.

July 1997: Establishment of a project director. Individual briefings between the project director, the Pro Vice-Chancellor with overall responsibility for the initiative and each of the heads of the 14 academic schools, to explain the goals and invite project proposals.

September 1997: First proposals received. Establishment of a formal steering committee to formulate policy and strategy.

During 1997/8 the 14 schools were reorganized into 6 faculties and in January 1998 a 
central team was put in place to interface with the new faculties. The role of these Learning Development Managers (LDMs) has been to help specific faculties to:

- Develop appropriate teaching, learning and assessment strategies.

- Develop teaching and learning proposals for internal and external funding.

- Identify and obtain resource-based learning materials produced elsewhere.

- Develop and implement learning support strategies and systems.

- Identify and meet staff development needs in relation to implementation of the Electronic Campus.

Successful project bids result in the formation of Project Teams within faculties. LDMs provide ongoing assistance and a link back to the central production resources (graphic design, courseware authoring, programming, desktop publishing, audio, video and photography, digitizing, print, etc.).

By April 1998 it was apparent that there was a need for an intermediate level of management between the Steering Group and the LDMs. An Operational Group of senior managers with responsibilities for key functions such as libraries and IT infrastructure was created to determine implementation uses and strategies.

In May 1998 a Web site was launched to support and publicize the initiative in conjunction with internal newsletter articles (13 to date).

September 1998: Hardware and software standards agreed.

\section{Costs}

It is not easy to cost a venture such as the Electronic Campus because it is not being developed ab initio. A lot of the costs would have been incurred anyway by the institution as part of its normal running costs. The following figures are an attempt to tease out some additional costs directly attributable to the initiative.

Not surprisingly the infrastructure costs are a significant element. A figure of $£ 400$ per student includes an allowance for network hardware and software installation, servers, access terminals and technical support. It is assumed for the purposes of the calculation that the ratio of terminals to students is 1 to 5 and that all staff have access to their own desktop machine.

The other significant costs are for learning materials and support systems development, including the costs of bought-in software. On average, each project costs around $£ 33,000$, split on a 60:40 ratio between faculties and the centre.

A cost that is easy to overlook is the amount of time spent by senior staff determining policy strategy and implementation plans. It is estimated that the Electronic Campus has cost approximately $£ 8,000$ p.a. so far pro rata.

\section{Problems}

As the number of projects under way has increased, it has been increasingly difficult to 
keep track of progress and to maintain the level of input necessary to guarantee minimum standards of quality. This highlights a trade-off to be made between embedding in local practice and quality control.

Inevitably there have been barriers to progress, which in some cases have resulted in slippage against project schedules. This experience highlights the need to retain some flexibility in delivery methods.

There are conflicting pressures for and against the early adoption of standards for hardware, development tools, delivery software, conferencing software, etc. Standards can reduce costs, staff development needs and product development times. Offset against this is the risk of committing too early to inappropriate tools and resistance to standards by staff interested in pursuing different avenues of development. This highlights the need to balance central coordination against the need for local autonomy and to postpone making commitments to standards until there is a high degree of confidence in their effectiveness and relevance.

There is also the potential for conflict with other organizational standards, for example, computing policies designed to maximize network integrity and data security may be at odds with the need for open and flexible access to learning materials, assessments and personal performance records. This highlights the need to ensure close collaboration between Electronic Campus developments and relevant operational arms of the university at the highest possible management levels. 'Bottom up' implementations are unlikely to be successful on an institutional scale.

The resource re-engineering model adopted here depends on being able to realign an increasing proportion of existing resources behind the new activities. Without convincing evidence of the benefits to staff, students, departments and the institution as a whole, it is very difficult to obtain the support required at resource manager level to sustain development. Evidence of this kind takes time to collect and present. This highlights the need for senior management commitment over an initial development and implementation phase of at least two years.

\section{Lessons learned}

\section{Money is not enough}

Aside from the infrastructure costs, the major Electronic Campus investment has been staff time, as buyout of staff from other normal duties and recruitment of additional staff. Money is not enough however to ensure adequate human resources. In our experience the faculty staff taking a lead in Electronic Campus have typically been heavily committed to other key activities as well, such as student recruitment, research, university consultancy, administration, etc. It has been difficult for such people to allocate as much time to Electronic Campus projects as they themselves would like. Other rewards need to be put in place such as recognition of the importance of teaching innovation and excellence.

\section{Champions at all levels}

Bottom-up approaches tend to founder on the rocks of competing policies and standards central to different parts of the institution. Staff eventually move on to other things and business returns to usual practices. On the other hand, a top-down, management-led, approach can be frustrated at the level of middle management where hard choices have to 
be made about resource allocations in the face of strong competing pressures. In order for innovation successfully to permeate the entire organization there have to be champions at all levels, ensuring an unbroken chain of commitment to the vision (Brown, 1997).

Faith versus evidence

Experiments need faith in the probability of desirable outcomes. On the other hand, wholesale institutional adoption of change needs convincing evidence. It takes time to build the evidence in a given organizational context and so experiments have to be given a reasonable period in which to prove themselves. In our experience, two years is an absolute minimum period for development and trialling.

\section{Central co-ordination versus local autonomy}

Top-down management is essential to ensure central co-ordination at a high enough level within the organization to ensure that inter-departmental differences do not present impossible barriers to innovation. Yet without a strong sense of local ownership in the faculties themselves, innovation is unlikely to be pursued wholeheartedly or sustained in the long term. Commitment is most likely to stem from local control over decision-making, so the temptation to control everything from the centre needs to be resisted.

\section{Standards versus flexibility}

From this it follows that while standards can be helpful in the early stages, they should not be imposed at the expense of constraining flexibility and creativity on the part of those expected to develop and implement the innovation. As the innovation gathers momentum and supporters, the need for greater co-ordination and agreement on standards can be allowed to emerge collectively.

\section{Keep it simple}

A university is a complex organizational form, which has evolved over hundreds of years. The Electronic Campus has had to be made operational within a year. On this timescale it has been important to make everything as easy as possible for the staff and students involved. The simplest, most familiar and most readily available tools have been selected to facilitate this process.

\section{References}

Brown, S. (ed.) (1997), Open and Distance Learning: Case Studies from Industry and Education, London: Kogan Page.

Cornwell, T. (1997), 'The University of the Highlands and Islands', paper for Using the Virtual University to Develop Capability, Higher Education for Capability Conference, Leeds, 27 June 1997.

Cunningham, S., Tapsall, S., Ryan, Y., Stedman, L., Bagdon, K. and Flew, T. (1998), 'New media and borderless education. A review of the convergence between global media networks and higher education provision', Department of Employment, Education, Training and Youth Affairs: Australia. http://www.deetya.gov.au/divisions/hed/highered/eippubs/ eip97-22.

Daniel, J. (1997), Mega-Universities and the Knowledge Media: Technology Strategies for Higher Education, London: Kogan Page. 
Ebeling, A. and Bistayi, S. (1997), 'Wired degrees: Forbes' 20 top Cyber-Us', http://www. forbes.com/forbes/97/0616/5912084a.htm.

Emery, F. E. and Trist, E. L. (1969), 'The causal texture of organizational environments', in Emery, F. E. (ed.), Systems Thinking, London: Penguin.

Hardy, D.W. (1997), 'Instructional design for distance education', Open Praxis 1, 26-9.

Hutton, J. L. (1998), 'What's the difference?' Open Praxis 1, 19-21.

Philips, V. and Yager, C. (1998), 'Best distance learning graduate schools: earning your degree without leaving home', Princeton Review Random House. See also http://www. geteducated.com/bestgrad.htm.

Romer, R. (1997), 'A matter of degrees', Educom Review, January/February, 17-23. 